\title{
Empatia e dor: interlocuções entre Edith Stein e Merleau-Ponty
}

\author{
Empathy and Pain: Interlocutions between Edith Stein \\ and Merleau-Ponty
}

\section{Iraquitan de Oliveira Caminha*}

Universidade Federal da Paraíba, João Pessoa, PB, Brasil

\section{Resumo}

O objetivo desse artigo é discutir a empatia do ponto de vista da perspectiva fenomenológica de Stein. Com base nessa leitura sobre a empatia, iremos correlacionar as concepções de corpo próprio de Stein e Merleau-Ponty, visando mostrar como a empatia pode ser compreendida como experiência intercorpórea. Depois de mostrar a empatia enquanto experiência intercorpórea, iremos considerar o problema de sentir a dor do outro no contexto da clínica psicanalítica. Finalmente, propomos pensar um quadro de fibromialgia para discutir o encontro com a dor do outro pela escuta flutuante do corpo do outro como obra de arte.

Palavras-chave: Empatia. Dor. Stein. Merleau-Ponty.

* IOC: Doutor em Filosofia, e-mail: caminhairaquitan@gmail.com 


\section{Abstract}

The aim of this article is to discuss empathy from the point of view of Stein's phenomenological perspective. Based on this reading on empathy, we will correlate Stein and MerleauPonty's conceptions of own body, in order to show how empathy can be understood as intercorporeal experience. After showing empathy as an intercorporeal experience, we will consider the problem of feeling the other's pain in the context of psychoanalytic clinic. Finally, we propose to think of a fibromyalgia picture to discuss the encounter with the other's pain by listening to the other's body as a work of art.

Keywords: Empathy. Pain. Stein. Merleau-Ponty.

\section{Introdução}

Nos dias 9, 10 e 11 de fevereiro de 2015, realizamos, na cidade de João Pessoa, o I Colóquio Internacional Estética e Existência, no Campus da Universidade Federal da Paraíba, para discutir as relações entre filosofar e viver criativo. Convidamos o professor Michel Dupuis da Université Catholique de Louvain para proferir uma conferência, intitulada "a glória do fenômeno" a partir da obra do poeta português Fernando Echevarría. A poesia de Echevarría foi considerada como exemplar para uma análise filosófico-estética do tema da glória do fenômeno, que não diz respeito simplesmente à visibilidade dos fenômenos, mas a sua profundidade, seu relevo e o seu enigma. Além de fazer essa conferência, o professor Dupuis realizou também, na cidade de João Pessoa, uma palestra sobre "empatia e pessoa humana em Edith Stein", no Espaço Psicanalítico - EPSI. Na ocasião, ele me presenteou o livro Le problème de l'empathie de Edith Stein; tradução do alemão para o francês, realizada por ele, da tese de doutorado da referida filósofa orientada por Edmund Husserl.

Passei a ler o texto de Edith Stein com o propósito de me apropriar do conceito de empatia e relacioná-lo com a clínica psicanalítica. Considerando que a tarefa de fazer a clínica é de se inclinar para ouvir 
o sofrimento do outro, torna-se indispensável pensar o tema da empatia no contexto da clínica. Se, para Stein, a empatia coloca em questão o problema do encontro com o "outro", a clínica psicanalítica pode encontrar, nas reflexões dessa filósofa sobre a empatia, um caminho para se pensar como é possível se ter acesso ao inconsciente do "outro".

Para pensar o problema da empatia, associado ao contexto da clínica psicanalítica, recorremos não somente a Edith Stein, mas também a Merleau-Ponty. Em nossa opinião, o modo como a filósofa e o filósofo discutem o corpo humano enquanto corpo próprio ou vivido, capaz de se entreolharem como expressão de singularidades, nos oferta um caminho para se pensar a clínica psicanalítica a partir da experiência da empatia.

Com base nessas considerações iniciais, propomos discutir a fenomenologia do encontro de Stein a partir da noção de empatia. Em seguida, correlacionar as concepções de corpo próprio de Stein e Merleau-Ponty, visando mostrar como a empatia pode ser compreendida como experiência intercorpórea. Depois, retomar a questão da empatia, considerando o problema de sentir a dor do outro no contexto da clínica psicanalítica. Finalmente, pensar um quadro de fibromialgia para discutir o encontro com a dor do outro pela escuta flutuante do corpo do outro como obra de arte.

\section{0 encontro: a empatia segundo Edith Stein}

A fenomenologia, enquanto método de investigação filosófica, se propõe a produzir discursos acerca daquilo que se mostra por si mesmo. É por essa razão que a fenomenologia busca a essência das coisas mesmas. Ela não se prende aos apriorismos racionalistas ou empiristas. $\mathrm{Na}$ intenção de descrever o modo como as coisas se apresentam à consciência, a perspectiva fenomenológica busca, por meio da intencionalidade, compreender como se dá o encontro entre a subjetividade e os objetos que se mostram. Esses objetos não são meras representações de algo exterior. Eles são compreendidos como fenômenos ou conteúdos vividos subjetivamente. Foi propósito de Husserl (1965) fazer da fenomenologia 
uma ciência rigorosa capaz de mostrar que o conhecimento científico não tem acesso ao objeto apenas em sua forma positiva ou natural, mas ao fenômeno enquanto vivido e carregado de sentido doado pela consciência.

Foi com base na fenomenologia, proposta por Husserl, que Edith Stein (2012) se colocou como desafio estudar a empatia. Para ela, a experiência de empatia advém de nossa condição existencial de ser no mundo como abertura para o outro. Assim, no mundo em que vivemos, enquanto pessoas em suas singularidades, não se pode reduzir o corpo às determinações físicas ou biológicas. Somos sujeitos viventes, percebidos como indivíduos psicofísicos irredutíveis às coisas físicas ou aos complexos orgânicos. Há entre os corpos humanos uma troca de experiências recíprocas vividas como empatia.

O corpo humano é capaz de se colocar em face de outro. É possível perceber a tristeza ou alegria de alguém ou até mesmo a simulação desses sentimentos por meio das expressões corporais. Um rosto pode ficar vermelho de vergonha ou de constrangimento. Edith Stein (2012) propõe o exemplo do encontro de dois amigos. Um fala para o outro que perdeu seu irmão. $\mathrm{O}$ amigo que escuta não somente compreende a fala que descreve um sofrimento, mas também é capaz de aperceber ou capturar a dor do outro pelo olhar. Compreender o sentido dessa experiência de entrar em contato com a dor do outro é atingir o coração da essência do que vem a ser empatia.

Muito provavelmente, a face daquele que relata a morte de seu irmão apresenta uma visão pálida e perturbada, bem como uma voz frágil e sufocada. A expressão verbal soma-se a essas manifestações visíveis. Mas tudo isso é da ordem da percepção direta da expressão do sofrimento. A empatia exige uma reflexão sobre o sentido dado por Stein à noção de "apercepção".

Aperceber a dor do outro é poder acolher a dor alheia na esfera do sentido. Desse modo, o alheio pertencente ao outro se faz presente a mim não somente por uma espécie de apoderamento perceptivo, mas também por uma leitura que elabora diferentes sentidos para aquilo que se percebe. Isso é possível porque somos capazes de nos reconhecermos como semelhantes. O poder de nos constituirmos como comunidade de próximos ou de seres afetivos nos oferece a possibilidade 
da experiência intercorpórea da empatia. Essa comunidade exige ao mesmo tempo reconhecimento de semelhanças e respeito às diferenças. Segundo Barea (2015, p. 38), "o encontro com o alheio, de imediato, conduz-nos a identificar-se como 'ser' de estrutura semelhante, porém portador de uma singularidade peculiar". A empatia é vivida por conta de uma reciprocidade de vivências semelhantes e, ao mesmo tempo, de uma diferenciação de significados singulares atribuídos às vivências.

A empatia como a atitude de ir ao encontro do outro não se traduz por uma elaboração coerente que constata, de maneira objetiva, o contato entre dois corpos. Do ponto de vista fenomenológico, a empatia levanta o problema da ação de se dirigir ao outro sem transformá-lo num objeto plenamente determinado. A empatia nos coloca num cenário aberto e intersubjetivo. Um em que se fazer presente ao outro pela empatia é um encontro marcado pela comunicação livre de todo enquadramento objetivo, que visa retirar do outro toda sua existência enigmática e misteriosa.

Aperceber a dor do outro como manifestação que não se reduz à aparência sensível objetivada é impossível de ser efetivado sem a facticidade da corporeidade do outro. $\mathrm{O}$ acesso à facticidade exige sempre um ato perceptivo. É claro que, para Stein, a dor nunca é uma coisa dada como um objeto visto externamente. Mas ela não se faz presente a mim se não tivermos acesso aos lampejos da dor que se faz visível pelo corpo do outro enquanto expressividade. A empatia não é uma percepção absolutamente externa, mas ela não se realiza sem a presença da face do outro que se mostra. Tal presença exige a intervenção da experiência perceptiva.

A empatia é essencialmente a experiência de encontro. Não basta a presença de dois corpos um em frente do outro. Faz-se necessária uma leitura da face do outro. É preciso um ato de tradução ou interpretação do que se passa com o outro. Reconhecemos que toda leitura é sempre arriscada, pois, enquanto elaboração, ela está sempre sujeita aos equívocos do erro. Por essa razão não se pode reduzir o outro a uma configuração de uma cartografia rígida que se estabelece enquanto traçados e contornos bem determinados. Quem sabe se uma reflexão sobre a noção de corpo próprio em Stein e Merleau-Ponty pode nos oferecer elementos preciosos para se considerar a intercorporeidade como reveladora da 
empatia enquanto experiência de encontro. Esse encontro, que é vivido como Einfühlung (empatia), significa sentir o outro na sua intimidade como alter ego do ponto de vista perceptivo e afetivo.

Vale ressaltar que Edith Stein (2012) adverte que a conexão entre um sentimento e uma expressão não é de natureza causal. O rosto vermelho, que expressa a raiva, ou o fechar dos punhos, que manifesta cólera, não contém uma conexão necessária entre uma expressão do corpo e uma revelação de um sentimento. A filósofa rejeita toda possibilidade de definir um processo causal entre um fenômeno que expõe o corpo e um vivido psíquico que expressa um sentimento. "Entre o sentimento e a expressão existe uma conexão de essência e de sentido, não de causalidade" (STEIN, 2012, p. 97). Nasce dessa compreensão a necessidade de se examinar o problema do corpo próprio ou o do corpo percebido, considerado aqui como aquele que nunca se reduz a uma representação da ciência em terceira pessoa.

\section{Intercorporeidade: corpo próprio em Stein e Merleau-Ponty}

A noção de corpo próprio, proposta por Edith Stein e MerleauPonty, é uma alternativa de superar a distinção radical entre sujeito e objeto proposta por Descartes. Ambos não acompanham a perspectiva cartesiana de separar corpo e consciência. Tal separação possibilita definir o corpo como objeto e atribuir à consciência total responsabilidade pela atividade psíquica.

O método fenomenológico é usado por Stein e Merleau-Ponty para mostrar que o corpo é, originariamente, um fenômeno vivido e não coisa física posicionada objetivamente no espaço e no tempo. Enquanto vivido, o corpo pode interagir com o outro e se perceber como um ser que se dirige para um outro ser. Desse modo, a unidade indissolúvel entre o eu e o seu próprio corpo nos possibilita considerar a empatia como uma experiência intercorpórea.

Torna-se possível considerar o corpo como sendo próprio porque a consciência é concebida como encarnada. A intencionalidade não é vista como meio para se ligar consciência - corpo - mundo. Ela é, 
na sua origem, intercorpórea, pois o corpo já é abertura para o mundo e para o outro pela percepção e pelos afetos. É pela motricidade que o corpo realiza movimentos que não são apenas mecânicos, mas expressão de desejos, vontades ou intenções cuja natureza é essencialmente perceptiva e afetiva. A experiência perceptiva nos põe em presença do outro, possibilitando uma afinidade intercorpórea que faz da empatia uma experiência de ação ou de movimento para o encontro com o outro. A receptividade do outro não é apenas uma experiência valorativa, mas, sobretudo, de natureza estética, compreendida aqui no sentido originário de experiência de sentir. Pensamos que a aproximação de Edith Stein e Merleau-Ponty, por meio da noção de corpo próprio, possibilita considerar a empatia como sendo fundamentalmente uma experiência estética em seu sentido "percepto-afetivo".

O sentido de propor a empatia no contexto de uma experiência estética encontra sua inspiração fundamental na noção do corpo obra de arte em Merleau-Ponty (1992). Para o filósofo, não é ao objeto físico que o nosso corpo deve ser comparado, mas antes de tudo a uma obra de arte. Mesmo admitindo que o corpo humano tenha uma base biológica determinada por razões bioquímicas, ele é sempre vivido ou experienciado a partir de contextos socioculturais. Merleau-Ponty considera que o corpo humano é marcado por um movimento de inacabamento e de abertura para a criatividade. Ele faz essa construção a partir de sua análise filosófica da obra de Cézanne.

O inacabamento das pinturas de Cézanne, procurando sempre uma nova forma de expressão, fez Merleau-Ponty (1966) correlacionar tal inacabamento com o caráter dinâmico e expressivo do corpo próprio, que está sempre em busca de novas elaborações para a sua vida. Desse modo, o corpo humano pode ser visto como uma "máquina imperfeita", sempre procurando produzir novas elaborações, que resultam na criação de diferentes estilos de vida. Nossas vulnerabilidade e precariedade nos abrem para o encontro com o outro e, ao mesmo tempo, nos lançam na aventura de nos reinventarmos cotidianamente enquanto corpo próprio. Do mesmo modo que a pintura de Cézanne não queria reproduzir o visível na tela, mas inventar o visível a partir de suas pinceladas, Merleau-Ponty concebia que o corpo humano 
não vivia para reproduzir a vida biológica, mas criar um modo de ser-no-mundo.

Mesmo admitindo que a noção de corpo próprio em Edith Stein é direcionada para pensar a empatia como sendo uma experiência interpessoal, pois o corpo próprio é o corpo tornando-se pessoa, não consideramos que isso seja impedimento para definir a empatia como sendo, ao mesmo tempo, uma experiência de natureza perceptiva, que exige um ato de receptividade do estranho e uma experiência afetiva de ser afetado pelo outro. Essas experiências são espontâneas, não exigindo daquele que as vivencia qualquer tipo de treinamento. A empatia enquanto experiência intercorpórea de sentir é própria da condição humana de se reconhecer no outro e de fazer com que o outro possa se reconhecer em mim. Tal reconhecimento não é uma mera analogia fruto de uma atividade consciente. Ele advém de uma interação que se estabelece por uma comunicação intercorpórea. Em nossa opinião, essa comunicação é vivida de maneira muito especial na situação clínica.

\section{Fibromialgia: a dor do outro pela escuta do corpo como obra de arte}

Falar sobre a dor é falar sobre si. Não compreendemos a dor como uma sensação qualquer configurada de maneira objetiva. $\mathrm{Na}$ clínica psicanalítica, a dor é sempre personalizada. O que nos interessa é o sentido atribuído à dor elaborado pelo paciente. Do ponto de vista fisiológico, a dor pode até ser semelhante para qualquer um que diz sentir dor. Mas, do ponto de vista psicossomático, a dor é uma expressão singular. É no campo da expressão singular que consideramos a fibromialgia. Nossa esperança é que, na clínica, essa dor difusa seja transformada em palavras. Esse processo de transformação simbólica exige um acolhimento da palavra, mas, sobretudo, um acolhimento do corpo próprio do outro, que requer uma experiência empática.

Recordo-me de Miriam, nome fictício, que conta sua história como se estivesse se contorcendo de dor na poltrona. A primeira vez que ela falou de sua dor, disse para ela: "você não está sozinha". Estou aqui para 
acolher a sua dor. Inspirado nas reflexões de corpo próprio de Edith Stein e Merleau-Ponty, compreendi que a atitude de acolher e recepcionar a dor alheia é um ato de encontro intercorpóreo. Reconheço que não posso efetivamente sentir a dor do outro, mas posso fazer com que a dor dele seja sentida por ele em minha companhia. Foi assim que lhe falei: "não sinto sua dor como você sente, mas você pode sentir sua dor comigo".

Nada é mais originário que a dor vivenciada por Miriam no seu corpo. Nesse sentido, a empatia nos leva a uma vivência que, segundo Stein (2012), é não-originária na medida em que estamos falando sempre de uma dor alheia que pode ser acolhida, mas nunca vivida originariamente enquanto uma vivência minha. A dor de Miriam nunca será um objeto diante de mim nem diante dela mesma. $\mathrm{O}$ que apreendemos é o sentido dessa dor vivida que pode ser ressignificado no processo de análise. Todavia, este sentido está encarnado no corpo próprio, pois não estamos falando do sentido como uma ideia desapegada do corpo.

Pelo corpo próprio, podemos considerar a dor de Miriam como presentificação empática da vivência alheia. Essa dor não está apenas nas aparências e nas narrativas de Miriam. A dor dela circula numa espécie de expressão empática que se comunica por uma relação de semelhança comigo que também sou um ser que sofre e tenho minhas dores. A empatia não produz em nossos corpos uma relação intercorpórea por meio de uma fusão que elimina as vivências das dores alheias. A empatia produz um encontro intercorpóreo que se estabelece pela semelhança e não pela identidade. Pela empatia, a dor do outro não pode ser sentida enquanto tal, mas pode ser compartilhada enquanto presença expressiva que se dirige para o outro.

Pelo corpo próprio a dor de Miriam se mostra ou se revela na clínica. Essa dor não é tomada como um objeto a ser explicado, mas como uma manifestação a ser reconhecida pela aproximação de dois corpos, que carregam consigo as marcas de uma subjetividade encarnada capaz de se mover em direção ao encontro do outro. A empatia possibilita um encontrar-se que nos coloca em relação com o outro. As atitudes de atração pela manifestação da simpatia, de retração pela antipatia ou de indiferença pela apatia serão sempre de segunda ordem. Pela empatia, podemos ter esse encontro repentino com a dor do outro. 
Aquele que sofre, pelo olhar da empatia, é sempre um vivente que vem ao nosso encontro. $\mathrm{O}$ destino que daremos a esse encontro é sempre uma questão a posteriori.

Em contato apenas com sensações descritas, uma espécie de fenomenologia da dor, foi possível experimentar a receptividade das dores difusas, da fadiga crônica, da rigidez muscular e das dores de cabeças intermináveis de Miriam. Para tudo isso não existe analgésico. Parece que a dor que se sente é a dor de viver. Talvez a experiência clínica possa permitir que o corpo que fala pela dor possa, um dia, quem sabe, encontrar a palavra para dizer o que não se sabe.

A atitude de acolhimento da dor estrangeira pode trazer o corpo que dói para um campo simbólico em que se expressa o sofrimento. Assim, posso me reconhecer no outro como sendo também um ser que sofre. Assemelhamo-nos pelo desamparo ou pela finitude. Houve um envolvimento imediato sem mediações que, com base em Edith Stein, chamaríamos de uma disposição para vivências com o outro. Essa disposição, segundo nossa opinião, é antes de tudo de natureza estética, enquanto encontro percepto-afetivo.

A empatia, como diz Edith Stein, é um ato de experiência que nos põe em contato imediato com o estrangeiro, o diferente. Não se apela aqui para uma representação do outro, mas para a sua presentificação. Não se pode querer tentar interpretar, traduzir ou decifrar expressões do outro sem que sua facticidade se faça presente em meu campo perceptivo. Assim, a empatia é a experiência de uma condição inexorável de ser afetado pelo outro. Destacamos aqui o sentido originário de Pathos como aquilo que nos afeta. Mesmo que nós possamos nos perguntar qual o destino que devemos dar ao encontro empático com o outro, nos exigindo uma postura ética, nós já estamos em contato empático com o outro pela irrecusável experiência estética de ser afetado inevitavelmente pelo outro.

Nesse momento, propomos descrever duas cenas da clínica que nos mobilizaram para considerar o problema da empatia numa perspectiva estética a partir de uma leitura percepto-afetiva da clínica psicanalítica, inspirada na noção de corpo próprio de Edith Stein e Merleau-Ponty. Numa sessão, a paciente descreve seu sofrimento e 
chora. Levanto-me da poltrona e oferto para ela um lenço de papel para que ela enxugasse suas lágrimas. Ela recebe o lenço e rasga-o, produzindo um monte de papel picado. Ela faz isso como se ali e naquele momento mostrasse como se sente: despedaçada, quebrada, estilhaçada, fraturada. Numa outra sessão, a paciente continua falando de seu sofrimento com os olhos cheios de lágrimas, repito a cena de me levantar e lhe oferecer um lenço de papel, mas, dessa vez, surpreendentemente, ela transforma o lenço de papel numa flor. Ela não somente se ressente de um passado cristalizado, mas passa a abrir novos horizontes de sentidos. Como se ali e naquele momento, ela revelasse um desejo de construção criativa. Seguindo os passos de Gilberto Safra, a pessoa do analista intui o que se passa com o corpo do outro pelo fato de seu próprio corpo estar sendo continuamente afetado pelo modo de existir do corpo do paciente (SAFRA, 2006).

\section{Considerações finais}

O ser humano é sempre um ser que sofre. O sofrimento é uma experiência fundamental que marca a vida de todo ser humano. Esse sofrimento não se revela apenas por uma disfunção orgânica do corpo concebido numa perspectiva puramente fisiológica. A saúde não pode ser reduzida às leituras funcionais, que são diagnosticadas por exames laboratoriais, desprovidos da fala daquele que sofre. A clínica considera a prosa do sujeito que expressa seu sofrimento. $\mathrm{O}$ clínico não deve apenas ter compaixão pelo sofrimento alheio. $\mathrm{O}$ se inclinar para ouvir o sofrimento do outro é, antes de tudo, constituir, com o outro, uma relação empática que exige uma postura de tomar para si a dor do outro. Isso não significa se apropriar dessa dor como se ela fosse um objeto factual desprovido de mistério.

O exercício fenomenológico de suspender todas as nossas certezas, conhecimentos, técnicas e convicções pessoais, visando possibilitar ao outro manifestar seu sofrimento como expressão de si, é uma atitude fundamental na clínica. Nesse sentido, antes do esforço psicanalítico para poder fazer prevalecer a regra de ouro da psicanálise 
(associação livre e escuta flutuante), é preciso instaurar com o outro, no cenário da clínica, uma relação empática. Não podemos negar que, para Freud (1912/1974), a clínica psicanalítica tem como foco a emergência do inconsciente por meio da posição de escuta silenciosa do analista e do livre falar do analisando. Desse modo, fala-se livremente, para que o inconsciente se manifeste, e fica-se atento, de forma flutuante, para que o inconsciente seja escutado. Todavia, a noção de empatia de Edith Stein nos faz ver que, antes de se instaurar um encontro semântico, a clínica psicanalítica estabelece um encontro intercorpóreo cuja natureza é empática.

Tanto para Merleau-Ponty como para Stein, a vida humana começa originariamente no corpo próprio. Para ambos, os corpos não são apenas meras máquinas que manifestam reações físico-químicas regidas por necessidades. O corpo, considerado por uma visão restritamente mecanicista, é contestado por ela e por ele. Nesse sentido, antes de ser reduzido a um conjunto de representações explicativas, conforme um modelo funcional da fisiologia, o corpo é vivido como abertura intencional para o outro. Freud se junta a Stein e a Merleau-Ponty para acrescentar que o corpo é originalmente um sistema pulsional que visa o prazer dos órgãos erotizados pelo outro. Podemos vislumbrar, na clínica psicanalítica, a presença do corpo considerado como próprio, concebido como sujeito da experiência de sentir e não como coisa integrada à natureza extensa das coisas, bem como a presença do corpo compreendido como pulsional, definido como existência erótica capaz de seduzir e de ser seduzido por forças afetivas.

O que é originário é a formação de um circuito empático entre o psicanalista e o cliente. É nesse circuito que é possível se ligar ao outro como corpos que se fazem pessoas pelas expressividades de seus modos de ser no mundo. É nessas expressividades, geradas num campo percepto-afetivo e não num cenário explicativo, que visualizamos a saúde criativa em oposição à saúde funcional. A dor não é apenas uma determinação funcional de um corpo doente que pede socorro, mas um modo de ser que é criado por um corpo que expressa sua vivência singular de sentir dor do seu jeito. O corpo que vive e percebe sua dor é o alvo da escuta psicanalítica. 
Os corpos do paciente e do analista, ambos dotados de sensibilidades diferentes, podem sentir tanto a dor física do cansaço ou do frio como a dor psíquica da tristeza e da angústia. Todavia, do ponto de vista do corpo próprio, não podemos considerar de maneira separada o físico e o psíquico. Por seguir um modelo clínico que não separa a dimensão física da esfera psíquica, propomos conceber uma saúde criativa que consiste em, mesmo estando ancorado na realidade atormentadora da dor, ser possível produzir soluções criativas para o sofrimento. Nessa perspectiva, o corpo visa um modo de ser saudável movido por uma potência poética capaz de se fazer singular enquanto presença expressiva para o outro. Desse modo, a dor do outro ganha a configuração de um rosto ou de uma pessoa que inventa uma linguagem própria, que somente pode se fazer presente na clínica psicanalítica quando for acolhida, por meio da atitude empática do corpo do analista.

\section{Referências}

BAREA, R. O tema da empatia em Edith Stein. Dissertação (Mestrado em Filosofia) - Programa de Pós-graduação em Filosofia, Universidade Federal de Santa Maria, Santa Maria, 2015.

FREUD, S. Recomendações aos médicos que exercem a psicanálise. In: Edição Standard Brasileira das Obras Completas Psicológicas de S. Freud (ESB). Rio de Janeiro: Imago Editora, 1974. v. XII. (Trabalho original de 1912).

HUSSERL, E. A Filosofia como Ciência de Rigor. Coimbra: Atlântida, 1965.

MERLEAU-PONTY, M. Phénoménologie de la perception. Paris: Gallimard, 1992. (Trabalho original de 1945).

MERLEAU-PONTY, M. Sens et non-sens. Paris: Nagel, 1966. (Trabalho original de 1948).

SAFRA, G. Hermenêutica na situação clínica: o desvelar da singularidade pelo idioma pessoal. São Paulo: Sobornost, 2006. 
CAMINHA, I. 0.

STEIN, E. Le problème de l'empathie. Paris; Toulouse: Ad Solem - Les Éditions du Cerf-Éditions du Carmel, 2012.

Recebido: 18/09/2017

Received: 09/18/2017

Aprovado: 27/09/2017

Approved: 09/27/2017 